\title{
National Approach to Premarital Diagnosis of Trait Thalassemia and Silent Carriers
}

\author{
Narges Beigom Mirbehbahani ${ }^{1}$, Azam Rashidbaghan ${ }^{2 *}$, Maryam Mazji ${ }^{2}$, Nasser Behnampour ${ }^{2}$ \\ ${ }^{1}$ Golestan University of Medical Sciences, Gorgan, Iran; ${ }^{2}$ Hematology and Oncology Research Center, Golestan University of Medi- \\ cal Sciences, Gorgan, Iran. \\ Email: *rashidbaghan@yahoo.com
}

Received October $6^{\text {th }}, 2012$; revised November $7^{\text {th }}, 2012$; accepted November $15^{\text {th }}, 2012$

\begin{abstract}
Background: Major $\beta$-thalassemia occurs when impaired genes received by a neonate from the parents. In most of the parents, there are no apparent clinical manifestation and they just show some impairments in hematological indices. This study was designed to determine prevalence of minor and silent carries parents that have children suffering from major $\beta$-thalassemia, compare it with national protocol about prevention of thalassemia. Methods: A blood sample was taken from parents of all major thalassemic patients covered by Taleghani Hospital in Gorgan $(\mathrm{n}=195)$, CBC and Hemoglobin electrophoresis were done. Data were analyzed using SPSS software. Results: Amongst 196 parents one case have normal level of $\mathrm{MCV}, \mathrm{MCH}, \mathrm{RBC}, \mathrm{HbA}, \mathrm{HbF}$ and mentzer $=22.05(0.51 \%)$ that diagnosed as alpha triplication $/ \mathrm{N}$ by real time PCR, RFLP informative. The means of hematological indices were based on the national protocol. Conclusion: Present results showed that there are a few cases of thalassemia disorders with normal $\mathrm{MCV}, \mathrm{MCH}, \mathrm{RBC}$, Mentzer index and $\mathrm{Hb}$ electrophoresis which could be missed in routine and pre-marital screening tests, resulted in a thalassemia child that it is possible in every screening test. Generally, indices were according to range of the national guideline.
\end{abstract}

Keywords: Beta-Thalassemia; Silent Carrier; Hemoglobin; Electrophoresis; Hematological Tests; Thalassemia Intermedia

\section{Introduction}

The inherited hemoglobin $(\mathrm{Hb})$ disorders are the most common single gene detect in men. The prevalence of hemoglobinopathies is on the rise worldwide. This is of special importance in developing countries where it increases the burden of health care delivery system. The abnormalities can either be quantitative (the thalassemia syndrome) or qualitative (the hemoglobin variants) or a combination of both. Of these, the thalassemia syndromes particularly the beta thalassemias and some aloha thalassemias are the major cause of morbidity [1].

Beta-thalassemia is the common hereditary disease all around the world, especially in Iran. It is estimated that 900,000 thalassemia patients will born in the next coming 20 years; which $95 \%$ of them will be in Asia, India and middle east. Iran Thalassemia Association reported that 18,616 thalassemia patients live in this country that Mazandaran and Fars have the most affected population [2].

Reduction or absence of beta globin chains of the hemoglobin results in Beta-thalassemia. The beta globin (HBB) chain gene is located on the short arm of chro-

${ }^{*}$ Corresponding author. mosome 11. Beta-thalassemia silent carrier, beta thalassemia trait, thalassemia intermediate and thalassemia major are four recognized category of this condition. Heterozygosis for beta-thalassemia will lead to betathalassemia silent carrier and trait [3]. In silent carrier often revealed mild microcytosis or a slight impairment in B-globin synthesis on radial labeling of the globin chains peripheral blood reticulocytes. Characteristically, silent carriers of $\beta$-thalassemia have normal levels of $\mathrm{HbA}_{2}$ [4]. Also silent carrier is known by normal or small decrease in $\mathrm{MCV}$ and $\mathrm{MCH}$ and normal hemoglobin electrophoresis [5]. This type will lead to a transfusiondependent baby if married with a minor thalassemia [6]. In 1969, a silent thalassemia was reported through examination not only of the hematological picture but also of the hemoglobin status and the $\alpha / \beta$ globin synthesis ratio; the carrier was undoubtedly the father of two thalassemia intermedia patients [7] in subsequent years many similar cases were observed that confirmed the existence of varieties of silent thalassemia [8-12].

In these patients increased RBC count, reduced hemoglobin level, $\mathrm{MCV}$ and $\mathrm{MCH}$, altered erythrocyte morphology and increased $\mathrm{HbA}_{2}$ level imbalance in globin 
synthesis with the $\alpha / \beta$ ratio greater than 1 [13]. Also they have microcytic and hypochromic anemia, target cells, basophilic aggregation and eliptocytosis, or can be normal appearance [14]. Hemoglobin ranges from 9 - 11 $\mathrm{gr} / \mathrm{dl}$, mean MCV is $68 \mathrm{fl}$ and $\mathrm{MCH}$ is around $20-22 \mathrm{gr}$ and $\mathrm{HbA}_{2}$ is greater than 3.5 [14-16].

Thalassemia intermediate is a clinical term that describes the transfusion status of the patient. In these patients who also homozygous for beta-thalassemia mutations based on family studies, a $\mathrm{Hb}$ concentrate of $6-10$ $\mathrm{gr} / \mathrm{dl}$, is maintained without blood transfusions [3].

The most severe form of thalassemia is thalassemia major that sufferer is transfusion-dependent due to severe anemia. High risk populations are detectable in Mediterranean region and screening programs are developing there to inform them about the best decision on reproductive choices associated with genetic counseling and prenatal diagnosis [17].

National screening program for detecting carrier couples (heterozygotes) was proved in Iran from 1991 to prevent the birth of major thalassemia, as a result of preventing the marriage of carriers, informing the couples for active participation in screening programs and genetic counseling [18].

In Iran, the annual prevention cost is constant but annual treatment costs rise year by year. National Thalassemia Prevention Program in the Iranian province of Mazandaran demonstrated that an unbearable financial burden can be prevented [19].

The main goal of the present project was determining $\mathrm{MCV}, \mathrm{MCH}, \mathrm{RBC}$ and hemoglobin electrophoresis in parents with thalassemia major child and evaluating that if these parents were at the time of national screening program could they be diagnosed as silent carriers or not (Figure 1).

\section{Materials and Methods}

This was a cross-sectional descriptive study. Generally, 196 individuals of parents of thalassemia major patients referred to Taleghani hospital of Gorgan, Iran, had been evaluated. This research was done during 2006-2007. All couples were married before the development of national screening program. Invitation letters were distributed for a free-of-charge testing as followings: $\mathrm{MCV}, \mathrm{MCH}, \mathrm{RBC}$, Mentzer index (MCV/RBC) and hemoglobin electrophoresis. A check list was filled for each person. Finally, all data were coded and entered into SPSS-15 software. Central and distributive parameters were calculated.

\section{Results}

In the present study 196 parents were tested. Mean and other parameters of studied subjects are shown in Tables 1 and 2.
Generally, among 196 persons, 194 (98.98\%) cases had $3.5 \% \leq \mathrm{HbA}_{2}$ and 2 cases had $3.5 \%>\mathrm{HbA}_{2}$.

$\mathrm{HbF}$ was $1.2 \% \leq$ for $129(66 \%)$ individuals and was $1.2 \%>$ for $69(44 \%)$ persons. Just one person $(0.51 \%$ of population) had $3 \% \leq \mathrm{HbF}$ and remaining individuals had $3 \%>\mathrm{HbF}$.

Mentzer index $>13$ was found in 45 persons $(23 \%)$ and the others had a mentzer index $<13$. One of the individuals with mentzer index $>13$ had $80 \leq \mathrm{MCV}$ and about others, it was $80>$. MCH for one person was $27 \leq$ and for others, it was $<27$. $\mathrm{HbA}_{2}$ was $3.5 \% \leq$ for 44 persons of them and for one of them was $3.5 \%>$. Among these persons, one had $3 \% \leq \mathrm{HbF}$ and $3.5 \% \leq \mathrm{HbA}_{2}$ and blood indexes were as fallowing: $\mathrm{HbA}=92.8, \mathrm{HbF}=3.4$, $\mathrm{HbA}_{2}=3.8, \mathrm{MCH}=22.85, \mathrm{MCV}=67.87$ and $\mathrm{RBC}=$ 4.42 .

In fact one of persons with mentzer index $>13$ had normal $\mathrm{MCH}, \mathrm{MCV}$ and $3.5 \%>\mathrm{HbA}_{2}$. That diagnosed as alpha triplication/ $\mathrm{N}$ by real time PCR, RFLP informative. The means of hematological indices were based on the national protocol.

Finally, 194 of 196 persons had $3.5 \% \leq \mathrm{HbA}_{2}$ and mentzer index for them was 8.09 - 18.37 with 11.99 as the mean count. This group was thalassemia minor with high $\mathrm{HbA}_{2}$. Just one person had $3 \% \leq \mathrm{HbF}, 3.5 \% \leq \mathrm{HbA}_{2}$ and mentzer index $=16.97$ that was thalassemia minor with high $\mathrm{HbA}_{2}$ and $\mathrm{HbF} .2$ individuals had $3.5 \%>$ $\mathrm{HbA}_{2}$. One of them had $80>\mathrm{MCV}, 27>\mathrm{MCH}$ and mentzer index $=12.78$ that was thalassemia minor with normal $\mathrm{HbA}_{2}$.

RT-PCR showed Alpha triplication/N in the affected mother and RFLP showed IVSI-130/N model in her husband, their thalassemic major child had IVSI-130/ Alpha triplication in RT-PCR.

\section{Discussion}

By researching, some studies on parents of patients with thalassemia major were as same as this study.

Ehteram et al. (1997) reported that in parents of thalassemia major patients, the mean of MCV is $60 \mathrm{fl}$ and for $\mathrm{MCH}, \mathrm{HbA}_{2}$ and $\mathrm{HbF}$ are 20, 5.2 and $2.4 \mathrm{pg}$, respectively [4]. In comparison to this study, our results had a larger rang of changes. While in our study, $98.98 \%$ of population had $3.5 \leq \mathrm{HbA}_{2}$ and in $1.02 \%$ of them, $\mathrm{HbA} 2$ was normal (3.5 > $\left.\mathrm{HbA}_{2}\right)$, Ehteram et al. (1997) demonstrated that in their study, $89.5 \%$ of persons have an electrophoresis disorder $\left(3.5<\mathrm{HbA}_{2}\right)$ and $10.5 \%$ of them had normal $\mathrm{HbA}_{2}$. There is markedly note that Ehteram and colleges didn't find any individuals with normal $\mathrm{HbA}_{2}$, MCV and MCH and all of cases had a disorder in hematological index. Probably, all parents were in beta thalassemia minor with normal $\mathrm{HbA}_{2}$ [4]. But in our investigation one of the persons with normal $\mathrm{HbA}_{2}$ and hemato 


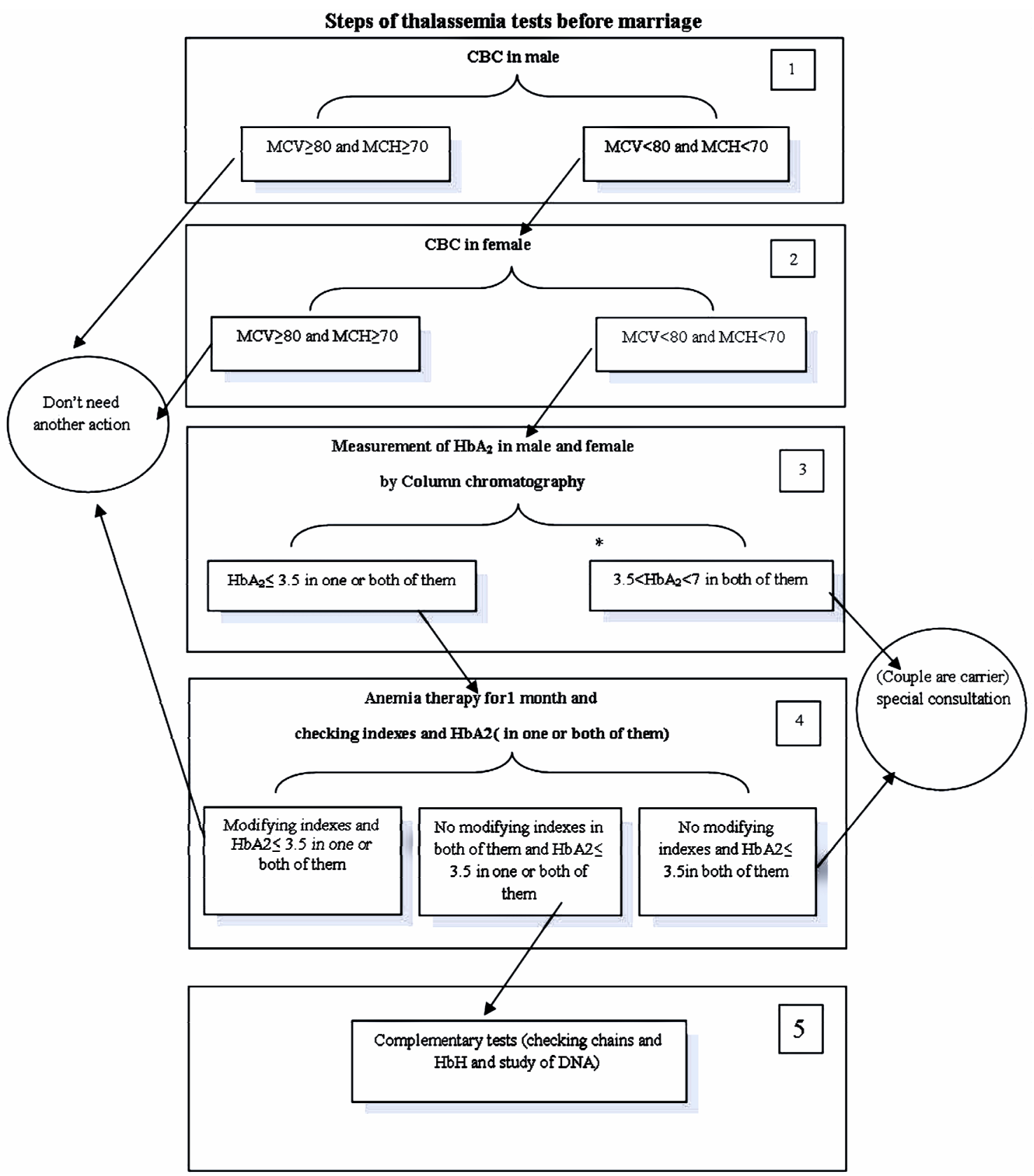

Figure 1. National screening program produced by Department of Genetic and Cancer, Deputy Non-communicable, Office of Disease Prevention Fight, Ministry of Health and Medical Education, Iran. "If $\mathrm{HbA}$ is $\geq 7$, person will be suspected to $\mathrm{Hbs}$, $\mathrm{HbG}, \mathrm{HbE}$ or HbC. It should be done acetate cellulose electrophoresis and citrate agar for definitive diagnosis.

Table 1. Hematologic indices of parents of patients with beta thalassemia.

\begin{tabular}{cccccccc}
\hline Index & Lower limit & Upper limit & Mean & Median & Mode & Standard division & Ranges \\
\hline MCV & 52.35 & $74.57^{* 1}$ & 62.65 & 62.08 & 59.43 & 4.38 & $\mathbf{3 5 . 8 6}$ \\
MCH & 14.26 & $25.9^{* 2}$ & 19.43 & 19.31 & 19.40 & 1.63 & $\mathbf{1 5}$ \\
RBC & $4.23 \times 10^{6}$ & $7.59 \times 10^{6}$ & $5.78 \times 10^{6}$ & $5.71 \times 10^{6}$ & $5.78 \times 10^{6}$ & $\mathbf{0 . 5 9}$ & $\mathbf{3 . 3}$ \\
Mentzer & $\mathbf{7 . 6 8}$ & $\mathbf{1 8 . 5 7}$ & $\mathbf{1 0 . 9 9}$ & $\mathbf{1 0 . 9 8}$ & $\mathbf{9 . 0 2}$ & $\mathbf{1 . 6 2}$ & $\mathbf{1 0 . 9}$ \\
\hline
\end{tabular}

${ }^{* 1}$ Except MCV of Alpha-triplication case that was $88.21 ;{ }^{* 2}$ Except MCH of Alpha-triplication case that was 29.26. 
Table 2. Central parameter and dispersion of electrophoresis index of parents of patients with beta thalassemia.

\begin{tabular}{ccccccccc}
\hline Index (\%) & Lower limit & Upper limit & Mean & Median & Mode & Standard division & Ranges \\
\hline HbA $_{\mathbf{1}}$ & 91.70 & 96.30 & 93.46 & 93.50 & 93.90 & 0.68 & $\mathbf{4 . 6 0}$ \\
$\mathbf{H b A}_{\mathbf{2}}$ & 3.00 & 6.90 & 5.18 & 5.20 & 4.70 & 0.80 & $\mathbf{3 . 9 0}$ \\
$\mathbf{H b F}$ & $\mathbf{0 . 4}$ & $\mathbf{3 . 4}$ & $\mathbf{1 . 3 5} \times \mathbf{1 0}^{\mathbf{6}}$ & $\mathbf{1 . 3 0}$ & $\mathbf{1 . 1 0}$ & $\mathbf{0 . 3 7}$ & $\mathbf{3 . 0 0}$ \\
\hline
\end{tabular}

logical index, had $13<$ mentzer index and likely was silent carrier. Probably, this difference is variety in geographic area and frequency of gene repeating in different populations.

Atapour et al. 1997, studied 197 parents with thalassemia major child in Kerman, Iran, and found MCV less than 70 in $90 \%, 70-80$ in $7.5 \%$ and upper than 80 in $2.5 \%$ (5 individuals) of population [17]. 2 of persons with MCV upper than 80 had normal $\mathrm{HbA}_{2}$, while in our study joust one person had $80 \leq \mathrm{MCV}$ and $27 \leq \mathrm{MCH}$ with normal $\mathrm{HbA}_{2}$. In our results, it was shown that all had MCV > 74.57 except for one. This exception had normal indices and was reported as a case of alpha-triplication that this result was similar to result of Atapour et al. 1997 [20].

Gholamreza Bahrami and colleagues, 1999, evaluated $\mathrm{HbA}_{2}$ and $\mathrm{HbF}$ for 38 parents with thalassemia major patients. Their results showed more contents than our results for these parameters and it was because of 2 persons with normal $\mathrm{HbA}_{2}$ in our result while in their study there weren't any persons with normal $\mathrm{HbA}_{2}$. Surely, their samples was less than our samples and probably, if they had a larger sample size, they would find cases with normal $\mathrm{HbA}_{2}$ [21].

In a study by Kattamis and colleagues (1997), on some families with at least one parent with normal $\mathrm{HbA}_{2}, 10 \%$ of all beta thalassemia patients had normal $\mathrm{HbA}_{2}$. Furthermore, some beta thalassemia patients with normal $\mathrm{HbA}_{2}$ with normal blood indexes have been found in their results. In this population, among 9 families, 6 of them were kwon as silent carrier and 3 of them were thalassemia minor with normal $\mathrm{HbA}_{2}$ [22]. While in our study, $1.02 \%$ of beta thalassemia was with normal $\mathrm{HbA}_{2}, 1 \%$ of parents were normal $\mathrm{HbA}_{2}$.

There are some studies about case report of beta thalassemia silent carrier in India, Italy and Albany [23-25], but generally, silent carrier have been considered lesser. Probably it is because of low frequency of silent carrier in different populations.

The results of this study showed that rare cases cannot be detected by screening system, so that alpha-triplication case was not found by screening algorithm. Thus, it is better to consider standards of studied population in screening. As the highest found value of $\mathrm{MCV}$ and $\mathrm{MCH}$ for parents with thalassemic children in this research, after omitting alpha-triplication case, was 74.57 and 25.9, respectively, it is suggested $\mathrm{MCV}$ and $\mathrm{MCH}$ are reduced from 80 and 27, respectively, to a lower number.

On the other hand, this delicacy has social consequences so that sometimes has been resulted that men and women prevent of marriage and finally has caused mental disorders and failure in marriage. Also it can make problems, especially, for girls as respect culture of our country and although they are not patient really but others think they are ill and these girls can not marry, While these persons have not any prohibition for marriage on the base of scientific indexes. Recommended genetic test that are done in special center, are costly for these persons. Meanwhile, according to obtained mod and median for MCV and MCH (Table 1), it seems we can use lesser value for $\mathrm{MCV}$ and $\mathrm{MCH}$.

\section{Conclusions}

In the present study no case of beta-thalassemia carrier was seen. Regardless to the alpha-triplication case, the least MCV was $74.57 \mathrm{fl}$ and the least $\mathrm{MCH}$ was $25.9 \mathrm{pg}$, mean MCV was $62.65 \mathrm{fl}$ and mean $\mathrm{MCH}$ was $19.43 \mathrm{pg}$.

Present results showed that there are a few cases of thalassemia disorders with normal $\mathrm{MCV}, \mathrm{MCH}, \mathrm{RBC}$, Mentzer indices and $\mathrm{Hb}$ electrophoresis which could be missed in routine and pre-marital screening tests, resulted in a thalassemia child that it is possible in every screening test. Generally, indices were according range the national guideline.

On the other hand, according to the cultures and religious condition of Iranian population, which having a disease is bad for a girl who is single; more attention should be paid to definite diagnosis of such a disease which could affect the relationships and marriage chances.

\section{Acknowledgements}

Authors tend to appreciate deputy of research in Golestan Medical University for the financial support of the project. This paper was derived from a doctorate thesis.

\section{REFERENCES}

[1] R. Sachdev, A. R. Dam and G. Tyagi, "Detection of $\mathrm{Hb}$ Variants and Hemoglobinopathies in Indian Population Using HPLC: Report of 2600 Cases," Indian Journal of Pathology and Microbiology, Vol. 53, No. 1, 2010, pp. 57-62. doi:10.4103/0377-4929.59185 
[2] M. B. H. Soteh, H. A. Niaki, M. Kowsarian, A. Aliasgharian and A. Banihashemi, "Frequency of Beta-Globin Gene Mutations in Beta-Thalassemia Patients from East of Mazandaran," Journal of Mazandaran University of Medical Sciences, Vol. 67, No. 18, 2008, pp. 17-25.

[3] A. Ahmadi A. R. M. Khalilabadi, M. Noroozi, N. Kohan and M. Ramzi, "Evaluation of Discrimination Indices Validity for Screening of $\beta$-Thalassemia Trait," Journal of Qom University of Medical Sciences, Vol. 3, No. 3, 2009, pp. 31-36.

[4] S. H. Oskie and D. G. Nathan, "The Thalassemia," In: D. G. Nathan, S. H. Oskie, D. Ginsburg and T. Look, Eds., Hematology of Infancy and Childhood, Sunders, Philadelphia, 2009, p. 1051.

[5] H. Ehteram and B. Shafaghi, "Laboratory Findings in Parents with Thalassemic Patients Referred to Imam Hossein Hospital 1997," Feyz Quarterly Journal of Kashan Medical University, Vol. 13, 2000, pp. 81-88.

[6] J. N. Luknes, "The Thalassemia and Related Disorders," In: G. R. Lee, J. Foerester, J. N. Luknes, J. P. P. Greer and G. Rodgers, Eds., Wintrobes Clinical Hematology, Sunders, Philadelphia, 1999, pp. 1421-1430.

[7] E. Schwartz, "The Silent Carrier of Beta Thalassemia," The New England Journal of Medicine, Vol. 281, No. 24, 1969, pp. 1327-1333. doi:10.1056/NEJM196912112812403

[8] M. Aksoy, G. Dincol and S. Erdem, "Different Types of Beta-Thalassemia Intermedia," Acta Haematologica, Vol. 59, No. 3, 1978, pp. 178-189. doi:10.1159/000207760

[9] C. Kattamis, A. Metaxotou-Mavromati, W. G. Wood, J. R. Nash and D. J. Weatherall, "The Heterogeneity of Normal Hb A2-b Thalassaemia," British Journal of Haematology, Vol. 42, No. 1, 1979, pp. 109-123.

[10] G. Aicardi, A. Naselli, G. V. Sciarratta and G. Sansone, "The Silent Carrier of Beta Thalassemia: Interaction with the Typical Beta Thalassemia Trait," Blut, Vol. 38, No. 6, 1979, pp. 473-478. doi:10.1007/BF01013508

[11] M. Aksoy, G. Bermek, G. Almis and A. Kutlar, " $\beta$-Thalassemia Intermedia Homozygous for Normal Hemoglobin A2 b Thalassemia. Study in Four Families," Acta Haematologica, Vol. 67, No. 1, 1982, pp. 57-61. doi:10.1159/000207025

[12] G. V. Sciarratta, M. I. Parodi, S. F. A. Vallerino and G. Sansone, "The Silent Carrier of $\beta$-Thalassemia," Annals of the New York Academy of Sciences, Vol. 445, 1984, pp. 111-118. doi:10.1111/j.1749-6632.1985.tb17180.x

[13] I. Bianco, M. P. Cappabianca, E. Foglietta, M. Lerone, G. Deidda, L. Morlupi, et al., "Silent Thalassemias: Genotypes and Phenotypes," Haematologica, Vol. 82, No. 3, 1997, pp. 269-280.

[14] S. H. Oskie and D. G. Nathan, "The Thalassemia," In: D. G. Nathan, S. H. Oskie, D. Ginsburg and T. Look, Eds., Hematology of Infancy and Childhood, Sunders, Phila- delphia, 2003, pp. 826-883.

[15] J. B. Edward, "Hemoglobin Disorders," In: D. L. Kasper, A. S. Fauci, D. L. Longo, E. Braunwald, S. L. Hauser, J. L. Jameson and J. Loscalzo, Eds., Harrison's Haematology and Oncology, Nasle Farda Publication, Tehran, 2005, pp. 105-114.

[16] A. Samavat and B. Modell, "Iranian National Thalassaemia Screening Programme," British Medical Journal, Vol. 329, No. 7475, 2004, pp. 1134-1137. doi:10.1136/bmj.329.7475.1134

[17] A. Cao and R. Galanello, "Beta-Thalassemia," Genetics in Medicine, Vol. 12, No. 2, 2010, pp. 61-76. doi:10.1097/GIM.0b013e3181cd68ed

[18] M. Kosaryan, A. Okhvatian and F. Babamahmoodi, "How Much We Have Been Successful in Nationwide Preventive Program for Beta-Thalassemia in Mazandaran University of Medical Sciences in 1992-2002," Journal of Mazandaran University of Medical Sciences, Vol. 4, No. 13, 2004, pp. 47-54.

[19] M. Karimi, S. Johari and N. Cohan, "Attitude toward Prenatal Diagnosis for $\beta$-Thalassemia Major and Medical Abortion in Southern Iran," Hemoglobin, Vol. 34, No. 1, 2010, pp. 49-54. doi:10.3109/03630260903547690

[20] M. Atapour, A. Zohoor, A. Zolali and A. Arjmand, "Hemoglobin A2 Percentage in Definite Carriers of Beta Thalassemia Major Patients Referred to Especial Disease Center in Kerman," Journal of Kerman University of Medical Sciences, Vol. 10, No. 2, 2003, pp. 99-104.

[21] G. H. Bahrami, H. Rahi and H. Dehghan, "Hemoglobin A2 and F Levels and Hematologic Parameters in Patients of Transfusion-Dependent Thalassemia Major Patients," Journal of Kermanshah University of Medical Sciences, Vol. 5, No. 2, 2001, pp. 6-12.

[22] C. Kattamis, A. Metaxotou Mavomati, W. G. Wood and J. R. Nash, "The Heterogeneity of Normal HbA2-Beta Thalassemia in Greec," British Journal of Hematology, Vol. 42, No. 1, 1997, pp. 109-123. doi:10.1111/j.1365-2141.1979.tb03703.x

[23] G. Aicardi, A. Naselli and F. Sciarratta, "Silent Carrier of $\beta$ Thalassemia: Interaction with Typical Beta Thalassemia Trait," Blut, Vol. 38, No. 6, 1979, pp. 473-478. doi:10.1007/BF01013508

[24] G. L. Semenza, K. Delgross, P. Malladi and Z. Schwart, "The Silent Carrier Allele: Beta Thalassemia a without Mutation in the Beta Globin Gene or Its Immediate Flanking Regions," Cell, Vol. 39, No. 1, 1984, pp. 123-128. doi:10.1016/0092-8674(84)90197-1

[25] A. Nad Korin, A. M. Pawar, V. C. Mudera, D. M. Mohanty and R. Colah, "Clinical Heterogeneity of Silent Gene $\beta$-Thalassemia among India," Annals of Hematology, Vol. 70, No. 1, 1995, pp. 61-64. 